\title{
Influence of salicylic acid on biochemical parameters and antioxidant system in mashbean plants grown under salt stress conditions
}

\author{
Manpreet Kaur ${ }^{1 *}$, Navita Ghai ${ }^{1}$, Jagmeet Kaur $^{2}$ and Inderjit Singh ${ }^{2}$ \\ ${ }^{1}$ Department of Botany, Punjab Agricultural University, Ludhiana -141004 (Punjab), INDIA \\ ${ }^{2}$ Department of Plant Breeding and Genetics, Punjab Agricultural University, Ludhiana -141004 (Punjab), INDIA \\ *Corresponding author. E-mail: sohalmanpreet87@gmail.com
}

Received: June 18, 2015; Revised received: July 24, 2016; Accepted: October 8, 2016

\begin{abstract}
Abiotic stress factors affect almost every aspect of physiology and biochemisrtry of a plant. The present study investigates the role of salicylic acid (SA) in inducing plant tolerance to salinity. The application of $0.5 \mathrm{mM}$ and $1.0 \mathrm{mM} \mathrm{SA}$ to mashbean (Vigna mungo L.) plants provided protection against $30 \mathrm{mM}$ or $45 \mathrm{mM} \mathrm{NaCl}$ stress through elevated antioxidant system. The genotypes KUG 363, KUG 310, (salt sensitive), KUG 502 and KUG 529 (salt tolerant) along with UL 338 (as check) were subjected to salt stress. Relative leaf water content (61\%) decreased under $45 \mathrm{mM}$ salt stress in salt tolerant genotype KUG 529 as compared to control (85\%). Leaf water potential was also recorded at 50 DAS in salt tolerant genotype KUG 529 (-2.66 mpa) and in salt sensitive genotype KUG 363(-3.76 $\mathrm{mpa}$ ).All the genotypes showed higher accumulation of Reactive Oxygen Species under salt stress. A remarkable decrease was shown in antioxidant enzymes like catalase (179 micro mole/min/g FW) and ascorbate peroxidase (1617 $\mathrm{n}$ moles/min/g FW) in KUG 529 . The level of antioxidant system was enhanced catalase (184 micro mole/ $\mathrm{min} / \mathrm{g} \mathrm{FW}$ ) and ascorbate peroxidase (1853 $\mathrm{n}$ moles/min/g FW) in mashbean plants under $\mathrm{NaCl}$ stress following SA applications. Thus SA helped in conferring stress tolerance to mashbean plants through enhanced antioxidant system. However, tolerant genotypes responded better than sensitive ones and lower concentration of SA (0.5mM) was more effective.
\end{abstract}

Keywords: Antioxidant enzymes, Mashbean, Salicylic acid, Salt stress

\section{INTRODUCTION}

The major problems in achieving higher yield are lack of exploitable genetic variability, poor harvest index and susceptibility to biotic and abiotic stress. Abiotic stress such as drought, salinity, extreme temperatures and chemical toxicity are serious threats to agriculture. Salt stress adversely affects crop productivity and quality. Salt stress is one of the major abiotic stress factors that affect almost every aspect of the physiology and biochemistry of the plant, resulting in reduction in its yield (Fahramand et al., 2014). Punjab is severely affected by salinity problem. About 85,000 ha of agricultural land is affected by waterlogging and salinity (Anonymous, 2009). Further, ground water in many parts of Punjab contains high concentration of dissolved salts with electrical conductivity between 2 to $7 \mathrm{dS} / \mathrm{m}$ (Shakya and Singh, 2010). Salinity has plagued soil fertility and drastically affected growth and survival of crop plants. A steady decrease in plant height under salinity stress was reported in cowpea (Hussein et al., 2007). Salinity reduces plant growth, alters ionic relation by ionic and osmotic effects and induces oxidative stress (Parida and Das, 2005; Silva et al., 2008; Molassiotis et al., 2006). Decrease in number of seeds per pod, number of pods per plant and severe reduction in seed yield per plant under increased salinity levels was reported in mungbean genotypes (Ahmad et al., 2005). Ghai et al. (2010) also recorded a significant decrease in yield percentage of mashbean genotypes grown under salt stress.

Mashbean (Vigna mungo L. Hepper) is the most important pulse crop in India and occupies a unique position in Indian agriculture. Its cultivation is about 3.26 million hectare and 1.74 million tones is its annual production with productivity of $5.34 \mathrm{Kg}$ (Anonymous, 2012). Although India is the main producer of mashbean but its production is limited due to various biotic and abiotic stresses (Ghai et al.,2014). A decrease in root and shoot fresh and dry weights of strawberry plants growing under saline conditions was reported by Karlidag et al. (2009). Salinity also leads to oxidative stress in plants due to production of reactive oxygen species (ROS). ROS are generated during metabolic processes damage cellular functions and consequently leads to disease, senescence and cell death (Joseph and Jini, 2011). The antioxidant enzymes such as Catalase, Ascrbate peroxidase and peroxidase showed variations in their activites under salt stress. Plants respond to stress by the synthesis of signaling molecules. Signaling molecules have been identified in plants such as calcium, jasmonic acid, ethyl- 
ene and salicylic acid (SA). These activate a range of signal transduction pathways. Salicylic acid(SA) is as an important signaling molecule for modulating plant responses to environmental stresses (Breusegem et al, 2001). However, there are few reports on the effects of salicylic acid on changes in antioxidant enzymes, ROS, membrane permeability of mashbean under salt stress. The increased activity of antioxidant enzymes also helps in overcoming the adverse effects of salt induced oxidative damage (Andre et al., 2006). Therefore, the present investigation was designed to assess the ameliorative effects of salicylic acid on salt stress in resistant and sensitive genotypes of mashbean.

\section{MATERIALS AND METHODS}

Seeds of five mashbean genotypes differing in salinity tolerance i.e. KUG 363 and KUG 310 (salt sensitive); KUG 502 and KUG 529 (salt tolerant) and UL 338 (recommended variety) were procured from the Department of Plant Breeding and Genetics, PAU, Ludhiana. $\mathrm{NaCl}$ (30 and $45 \mathrm{mM}$ ) was applied in split dose (at the time of sowing and 15 days after sowing). Controls were irrigated with tap water. Foliar application of SA (a) $0.5 \mathrm{mM}$ and $1 \mathrm{mM}$ was done at $25 \mathrm{DAS}$ on salt stressed plants. All the genotypes were subjected to following treatments:

$\mathrm{T}_{1}$ (Control), $\mathrm{T}_{2}(\mathrm{NaCl} 30 \mathrm{mM}), \mathrm{T}_{3}(\mathrm{NaCl} 45 \mathrm{mM}), \mathrm{T}_{4}$ $(\mathrm{NaCl} 30+\mathrm{SA} 0.5 \mathrm{mM}), \mathrm{T}_{5}(\mathrm{NaCl} 45+\mathrm{SA} 0.5 \mathrm{mM}), \mathrm{T}_{6}$ $(\mathrm{NaCl} 30+\mathrm{SA} 1.0 \mathrm{mM}), \mathrm{T}_{7}(\mathrm{NaCl} 45+\mathrm{SA} 0.5 \mathrm{mM})$.

The data on following physiological, biochemical and yield contributing parameters were studied at flowering stage (50DAS).

Relative water content (RWC): The relative water content was estimated based on Barz and Weatherley method (1962) and the relative water content (RWC) of leafs was calculated as: RWC $=100 \times[$ (fresh mass dry mass) / (saturated mass - dry mass)]. Saturated mass was determined after incubation of the leaf in water for $24 \mathrm{~h}$ at room temperature. Dry mass was measured following oven drying at $75^{\circ} \mathrm{C}$ to a constant mass.

Leaf water potential: Leaf water potential was measured with Wescor water potential system.

Electrolyte leakage: Electrolyte leakage from membranes of leaf tissue was estimated by the method described by Bajji et al., 2001 and expressed as per cent electrolyte leakage.

Measurement of malonaldehyde content (MDA), hydrogen peroxide content and acitivites of antioxidant enzymes: All samples were prepared for MDA, $\mathrm{H}_{2} \mathrm{O}_{2}$ and enzyme analyses by homogenisation of the fresh tissue in a solution (4 $\mathrm{ml} \mathrm{g-1} \mathrm{fresh} \mathrm{weight)} \mathrm{con-}$ taining phosphate buffer. After the homogenate was centrifuged at $12,000 \times \mathrm{g}$ for $20 \mathrm{~min}$ at $4^{\circ} \mathrm{C}$, the supernatant was used to determine the enzymatic activities (Cho and Park, 2000). The MDA content was measured using the thiobarbituric acid (TBA) reaction as described by Heath and Packer, (1969). Hydrogen per- oxide content was estimated following the method given by Velikova et al., 2000.

The POD activity was determined according to the method of Chance and Maehly (1995). Changes in absorbance of the reaction solution at $470 \mathrm{~nm}$ were recorded every 20 seconds. The CAT activity was measured using the method of Dhindsa and Motowe, (1981). The ascorbate peroxidase (APX) activity was measured by the decrease in absorbance at $290 \mathrm{~nm}$ as the ascorbate was oxidised (Nakano and Asada, 1981). The data was statistically analysed using CPCS1 software to calculate $\mathrm{CD}$ at $5 \%$ level of significance.

\section{RESULTS AND DISCUSSION}

Results of the present study showed that overall reduction in physiological and biochemical parameters are due to salt stress. Various genotypes differed significantly from each other in amelioration of $\mathrm{NaCl}$ stress by $\mathrm{SA}$.

Relative leaf water content: Salt stress caused reduction in RLWC of the leaves at flowering stage of all the genotypes. Also this decrease $(20 \%)$ was more pronounced in sensitive genotype (KUG 363) than the tolerant one (KUG 529) as shown in fig. 1. However treating the plants with SA caused an improvement in RLWC, with lower concentration of SA $(0.5 \mathrm{mM})$ being more effective in $30 \mathrm{mM} \mathrm{NaCl}$ stressed plants and tolerant genotypes responded more than sensitive ones. A decrease in water availability under soil salinity causes osmotic stress, which leads to a decreased turgor. Reduced RLWC under the influence of salt stress has been reported by El-Bassiouny and Bekheta, (2005) in wheat and Mohammadreza (2012) in Brassica napus. SA treatments induced an increase in RLWC of the stressed plants compared to the nontreated plants in all these crops.

Leaf water potential: Increasing salinity caused a decrease in water potential i.e. it became more negative in all genotypes. Similar observations were recorded by Kaur (2009) in salt stressed mashbean plants.

Foliar application of SA $(0.5 \mathrm{mM}$ and $1.0 \mathrm{mM})$ caused an improvement in water potential to some extent as shown in fig. 2. $0.5 \mathrm{mM}$. SA proved to be more effective in tolerant and sensitive genotypes at $30 \mathrm{mM} \mathrm{NaCl}$. A decrease in leaf water potential was reported by Parida \& Das (2005) and Cheng-Wu Jin et al., 2012) in Kenaf cultivars when salinity stress was imposed. Salinity acts to inhibit plant access to soil water by increasing the osmotic strength of soil solution. As the soil dries, the soil solution becomes increasingly concentrated, thus lowering the soil water potential, thereby limiting the plant access to soil water. Kaur (2011) also reported an improvement in water potential of salt stressed mashbean plants following SA applications

Membrane stability index: Electrolyte leakage enables cell membrane injury to be assessed when plants are subjected to stress. The increase in membrane permeability was found to be in $\mathrm{NaCl}$ concentration de- 


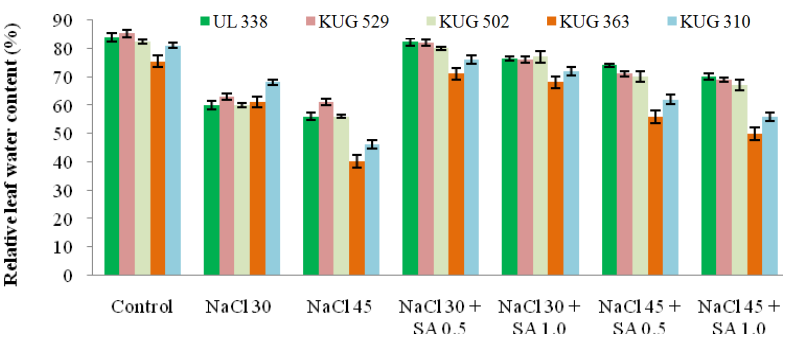

Fig. 1. Effect of $\mathrm{NaCl}$ and $\mathrm{SA}$ treatments on relative leaf water content.

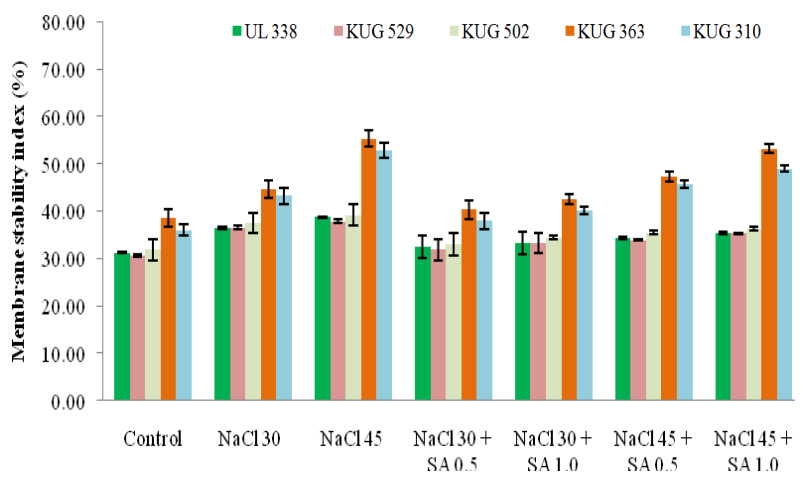

Fig. 3. Effect of $\mathrm{NaCl}$ and $\mathrm{SA}$ treatments on membrane permeability.

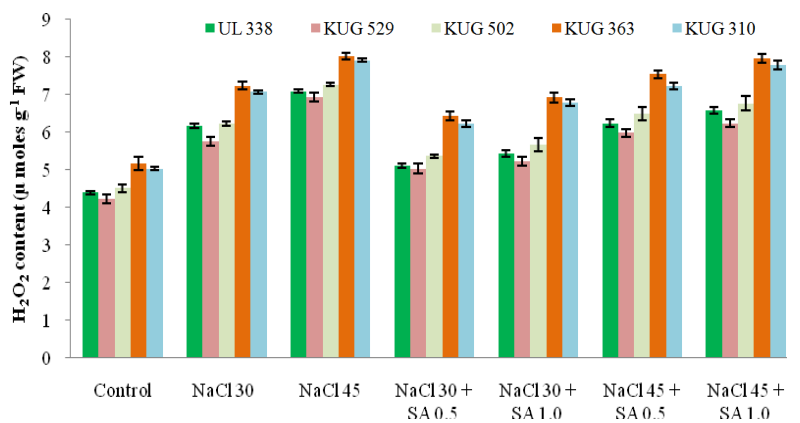

Fig. 5. Effect of $\mathrm{NaCl}$ and $\mathrm{SA}$ treatments on hydrogen Peroxide content.

pendent manner i.e. $45 \mathrm{mM} \mathrm{NaCl}$ causing more electrolyte leakage from the membrane as compared to $30 \mathrm{mM}$ $\mathrm{NaCl}$. Treatment of salt stressed plants with SA $(0.5 \mathrm{mM}$ nd $1.0 \mathrm{mM})$ helped in overcoming the adverse effects of salinity by restoring the membrane permeability. Salinity induced increase in electrolyte leakage and its amelioration by SA application has been reported earlier by Gunes et al. (2007) in maize and Khan et al., (2010) in cucumber. Mohammadreza, (2012) also reported an increase in electrolyte leakage in salt stressed Brassica napus seedlings. SA facilitated maintenance of membrane functions through induction of antioxidant mechanisms.

Malondialdehyde content (MDA): Lipid peroxidation measured as MDA content is considered to be an indicator of oxidative damage from stress (Sevengor et al., 2011). In the present investigation, salt sensitive

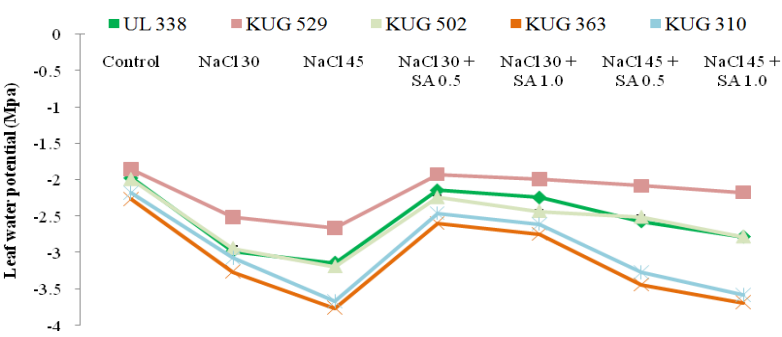

Fig. 2. Effect of $\mathrm{NaCl}$ and $\mathrm{SA}$ treatments on Leaf water potential.

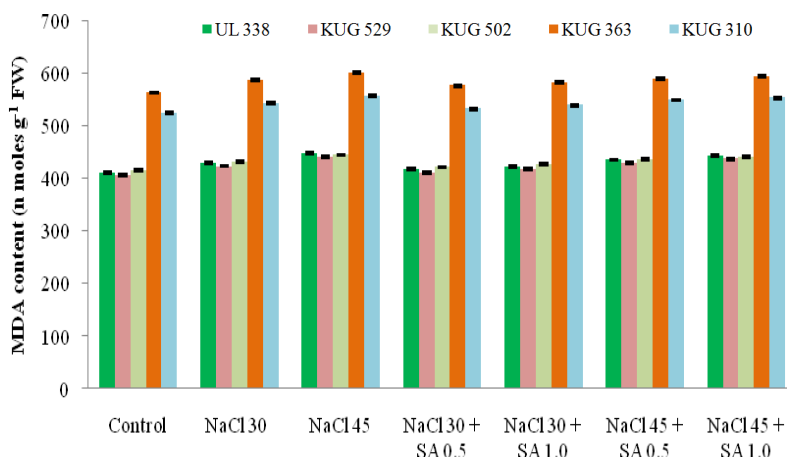

Fig. 4. Effect of $\mathrm{NaCl}$ and $\mathrm{SA}$ treatments on MDA content.

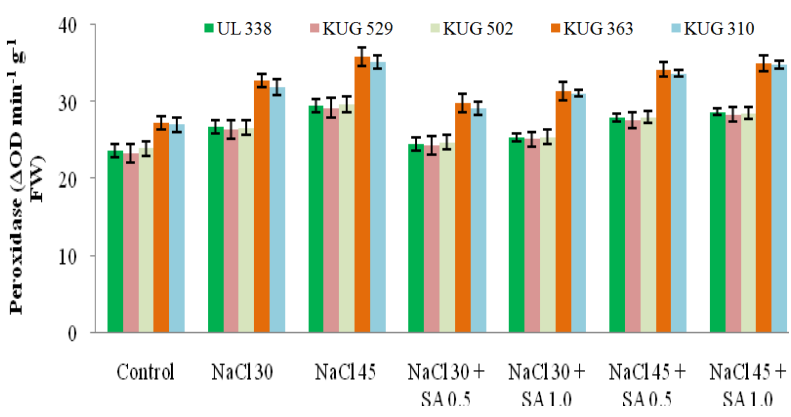

Fig. 6. Effect of $\mathrm{NaCl}$ and $\mathrm{SA}$ treatments on peroxidase activity.

genotypes showed more accumulation of MDA content as compared to salt tolerant ones and application of SA (0.5 and $1 \mathrm{mM})$ helped in reducing its level. Simaei et al. (2011) also observed that MDA content declined in soybean treated with $\mathrm{SA}$ in the presence of $50 \mathrm{mM}$ $\mathrm{NaCl}$. Salinity significantly increased MDA content in Basil plants and treating the plants with SA decreased lipid peroxidation decreased based on MDA measurement in the salt stressed plants (Delavari et al., 2010). Our study revealed that $0.5 \mathrm{mM}$ SA was more effective in reducing the MDA content in all the genotypes growing under $30 \mathrm{mM} \mathrm{NaCl}$.

Hydrogen peroxide content $\left(\mathrm{H}_{2} \mathrm{O}_{2}\right)$ : Under the influence of salt, $\mathrm{H}_{2} \mathrm{O}_{2}$ content increased in mashbean genotypes. However, application of SA declined the concentration of $\mathrm{H}_{2} \mathrm{O}_{2}$ in all the genotypes with more decline in tolerant as compared to sensitive genotypes. 


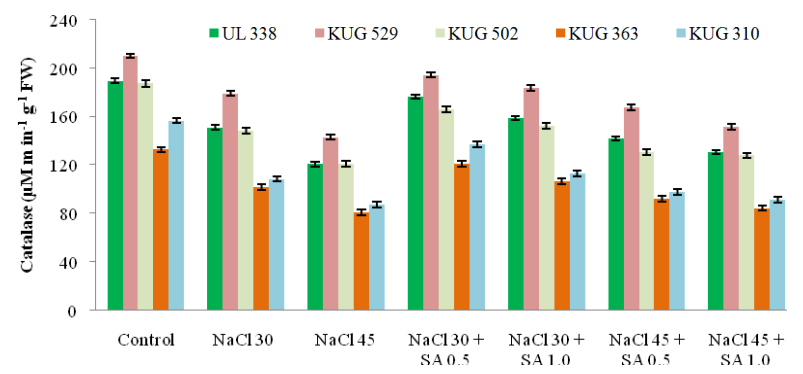

Fig. 7. Effect of $\mathrm{NaCl}$ and $\mathrm{SA}$ treatments on catalase activity.

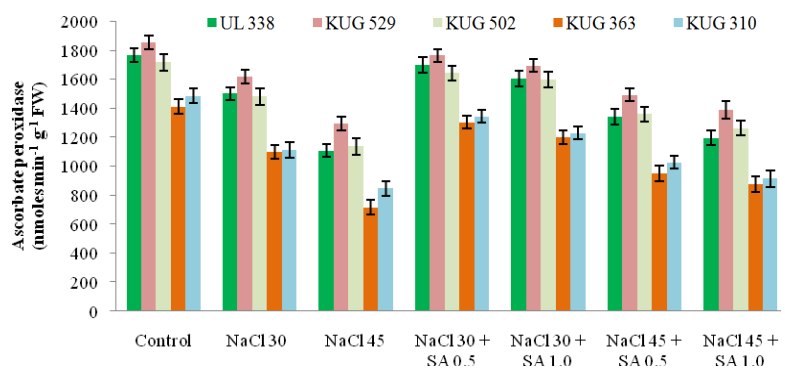

Fig. 8. Effect of $\mathrm{NaCl}$ and $\mathrm{SA}$ treatments on ascorbate peroxidase activity.

Table 1. Effect of $\mathrm{NaCl}$ and salicylic acid treatments on number of pods plant ${ }^{-1}$ in mashbean genotypes.

\begin{tabular}{|c|c|c|c|c|c|}
\hline \multirow{2}{*}{ Treatments } & \multicolumn{5}{|c|}{ Genotypes } \\
\hline & UL 338 & KUG 529 & KUG 502 & KUG 363 & KUG 310 \\
\hline Control & $39.2 \pm 1.85$ & $44.5 \pm 0.87$ & $31.4 \pm 1.33$ & $27.8 \pm 0 / 74$ & $29.2 \pm 0.74$ \\
\hline $\mathrm{NaCl} 30$ & $30.5 \pm 1.73$ & $30.3 \pm 0.95$ & $24.5 \pm 1.15$ & $17.6 \pm 0.70$ & $18.4 \pm 1.48$ \\
\hline $\mathrm{NaCl} 45$ & $29.8 \pm 1.67$ & $29.5 \pm 1.28$ & $21.2 \pm 1.73$ & $15.2 \pm 0.84$ & $16.5 \pm 1.42$ \\
\hline $\mathrm{NaCl} 30+\mathrm{SA} 0.5$ & $37.0 \pm 0.69$ & $38.2 \pm 1.44$ & $30.6 \pm 0.16$ & $24.7 \pm 0.87$ & $26.5 \pm 1.15$ \\
\hline $\mathrm{NaCl} 30+\mathrm{SA} 1.0$ & $36.5 \pm 0.67$ & $36.1 \pm 1.45$ & $30.4 \pm 1.85$ & $22.5 \pm 0.91$ & $25.7 \pm 0.92$ \\
\hline $\mathrm{NaCl} 45+\mathrm{SA} 0.5$ & $32.6 \pm 0.67$ & $34 \pm 1.27$ & $29.7 \pm 0.87$ & $20.8 \pm 1.73$ & $21.3 \pm 0.85$ \\
\hline $\mathrm{NaCl} 45+\mathrm{SA} 1.0$ & $30.0 \pm 0.70$ & $32.6 \pm 1.50$ & $28.1 \pm 0.91$ & $19.6 \pm 1.96$ & $20.6 \pm 0.89$ \\
\hline
\end{tabular}

Table 2. Effect of $\mathrm{NaCl}$ and salicylic acid treatments on seeds $\operatorname{pod}^{-1}$ in mashbean genotypes.

\begin{tabular}{lccccc}
\hline \multirow{2}{*}{ Treatments } & \multicolumn{5}{c}{ Genotypes } \\
\cline { 2 - 6 } & UL 338 & KUG 529 & KUG 502 & KUG 363 & KUG 310 \\
\hline $\mathrm{Control}$ & $6.1 \pm 0.29$ & $6.3 \pm 0.18$ & $6.0 \pm 0.24$ & $5.3 \pm 0.08$ & $5.4 \pm 0.12$ \\
$\mathrm{NaCl} 30$ & $5.3 \pm 0.12$ & $5.4 \pm 0.12$ & $5.6 \pm 0.14$ & $4.7 \pm 0.10$ & $4.8 \pm 0.20$ \\
$\mathrm{NaCl} 45$ & $4.9 \pm 0.13$ & $5.2 \pm 0.13$ & $5.3 \pm 0.14$ & $4.2 \pm 0.08$ & $4.4 \pm 0.21$ \\
$\mathrm{NaCl} 30+\mathrm{SA} 0.5$ & $6.0 \pm 0.10$ & $6.0 \pm 0.12$ & $5.7 \pm 0.13$ & $4.9 \pm 0.12$ & $5.0 \pm 0.19$ \\
$\mathrm{NaCl} 30+\mathrm{SA} \mathrm{1} .0$ & $5.8 \pm 0.17$ & $6.0 \pm 0.24$ & $5.8 \pm 0.16$ & $5.1 \pm 0.09$ & $5.1 \pm 0.23$ \\
$\mathrm{NaCl} 45+\mathrm{SA} 0.5$ & $5.4 \pm 0.21$ & $5.5 \pm 0.23$ & $5.9 \pm 0.08$ & $4.8 \pm 0.19$ & $5.0 \pm 0.10$ \\
$\mathrm{NaCl}$ 45 + SA 1.0 & $5.5 \pm 0.19$ & $6.0 \pm 0.25$ & $5.8 \pm 0.08$ & $4.9 \pm 0.18$ & $4.9 \pm 0.10$ \\
$\mathrm{CD}(\mathrm{p}=0.05)$ Genotypes $=0.18$, Treatments $=0.21$, Genotypes x Treatments $=\mathrm{NS}$ & & \\
\hline
\end{tabular}

Table 3. Effect of $\mathrm{NaCl}$ and salicylic acid treatments on 100-seed weight $(\mathrm{g})$ of mashbean genotypes.

\begin{tabular}{|c|c|c|c|c|c|}
\hline \multirow{2}{*}{ Treatments } & \multicolumn{5}{|c|}{ Genotypes } \\
\hline & UL 338 & KUG 529 & KUG 502 & KUG 363 & KUG 310 \\
\hline Control & $4.28 \pm 0.17$ & $4.44 \pm 0.15$ & $4.29 \pm 0.17$ & $4.04 \pm 0.13$ & $4.05 \pm 0.28$ \\
\hline $\mathrm{NaCl} 30$ & $3.51 \pm 0.18$ & $3.95 \pm 0.09$ & $3.88 \pm 0.23$ & $3.45 \pm 0.10$ & $3.57 \pm 0.29$ \\
\hline $\mathrm{NaCl} 45$ & $3.42 \pm 0.16$ & $3.83 \pm 0.12$ & $3.68 \pm 0.19$ & $3.26 \pm 0.20$ & $3.50 \pm 0.21$ \\
\hline $\mathrm{NaCl} 30+\mathrm{SA} 0.5$ & $4.07 \pm 0.22$ & $4.40 \pm 0.11$ & $4.15 \pm 0.17$ & $3.98 \pm 0.21$ & $4.01 \pm 0.31$ \\
\hline $\mathrm{NaCl} 30+\mathrm{SA} 1.0$ & $4.03 \pm 0.14$ & $4.12 \pm 0.20$ & $4.04 \pm 0.31$ & $3.86 \pm 0.25$ & $4.00 \pm 0.17$ \\
\hline $\mathrm{NaCl} 45+\mathrm{SA} 0.5$ & $3.98 \pm 0.12$ & $4.01 \pm 0.06$ & $4.00 \pm 0.29$ & $3.76 \pm 0.24$ & $3.78 \pm 0.25$ \\
\hline $\mathrm{NaCl} 45+\mathrm{SA} 1.0$ & $3.91 \pm 0.14$ & $3.99 \pm 0.10$ & $3.98 \pm 0.18$ & $3.66 \pm 0.23$ & $3.77 \pm 0.30$ \\
\hline
\end{tabular}

$0.5 \mathrm{mM}$ SA caused $13 \%$ reduction in tolerant genotypes while sensitive genotypes showed $11 \%$ reduction in $\mathrm{H}_{2} \mathrm{O}_{2}$ content in plants growing under $30 \mathrm{mM} \mathrm{NaCl}$ (Figure 5). The serious damage caused by salt stress is at least partially due to the generation of reactive oxygen species (ROS), such as superoxide and hydrogen peroxide. An increase in $\mathrm{H}_{2} \mathrm{O}_{2}$ content in the wheat seedlings under high salinity was observed by Erdal et al. (2011). Of all the genotypes studied KUG 529 showed significantly lesser $\mathrm{H}_{2} \mathrm{O}_{2}$ content which might be contributing towards its salt tolerant behavior.

Peroxidase activity (POX): Application of $45 \mathrm{mM}$ $\mathrm{NaCl}$ caused more increase in POX activity in leaves of mashbean genotypes as compared to $30 \mathrm{mM} \mathrm{NaCl}$ 
Manpreet Kaur et al. / J. Appl. \& Nat. Sci. 8 (4): 1786-1792 (2016)

Table 4. Effect of $\mathrm{NaCl}$ and salicylic acid treatments on seed yield plant ${ }^{-1}$ (g)of mashbean genotypes.

\begin{tabular}{|c|c|c|c|c|c|}
\hline \multirow{2}{*}{ Treatments } & \multicolumn{5}{|c|}{ Genotypes } \\
\hline & UL 338 & KUG 529 & KUG 502 & KUG 363 & KUG 310 \\
\hline Control & $10.36 \pm 1.39$ & $12.81 \pm 0.17$ & $8.16 \pm 1.00$ & $5.89 \pm 0.26$ & $6.26 \pm 0.75$ \\
\hline $\mathrm{NaCl} 30$ & $5.69 \pm 0.50$ & $6.46 \pm 0.21$ & $5.37 \pm 0.69$ & $2.87 \pm 0.26$ & $3.11 \pm 0.13$ \\
\hline $\mathrm{NaCl} 45$ & $4.99 \pm 0.38$ & $5.86 \pm 0.23$ & $4.10 \pm 0.02$ & $2.18 \pm 0.20$ & $2.64 \pm 0.19$ \\
\hline $\mathrm{NaCl} 30+\mathrm{SA} 0.5$ & $9.01 \pm 0.16$ & $10.07 \pm 0.32$ & $7.25 \pm 0.42$ & $4.81 \pm 0.31$ & $5.26 \pm 0.04$ \\
\hline $\mathrm{NaCl} 30+\mathrm{SA} 1.0$ & $8.45 \pm 0.19$ & $8.90 \pm 0.42$ & $7.13 \pm 0.79$ & $4.44 \pm 0.39$ & $5.22 \pm 0.26$ \\
\hline $\mathrm{NaCl} 45+\mathrm{SA} 0.5$ & $6.99 \pm 0.09$ & $7.48 \pm 0.13$ & $6.97 \pm 0.21$ & $3.84 \pm 0.71$ & $4.01 \pm 0.19$ \\
\hline $\mathrm{NaCl} 45+\mathrm{SA} 1.0$ & $6.43 \pm 0.23$ & $7.77 \pm 0.16$ & $6.46 \pm 0.01$ & $3.60 \pm 0.70$ & $3.78 \pm 0.22$ \\
\hline
\end{tabular}

Concentrations used were in $\mathrm{mM}$.

stress. Treating the plants with SA $(0.5 \mathrm{mM}$ and $1.0 \mathrm{mM})$ decreased the activity level of POX in all the genotypes including check variety UL 338 .

Erdal et al. (2011) reported that salt stress significantly increased the activity of POX in wheat genotypes. Foliar applications of SA caused a reduction in activity level of POX as compared to salt grown plants, but it was more than non- saline control plants. Purcarea and Cachiţa-Cosma, (2010) observed a decrease in activity of POX enzyme under the combined influence of salt and SA in maize.

Catalase activity (CAT): Figure 7 shows the effect of SA on the catalase activity of mash genotypes grown under salt stress. Salt stress at both the concentrations decreased the catalase activity and this decrease was in a concentration dependent manner. However, under the influence of SA, an increase in activity was recorded and it was more pronounced in the salt-tolerant than in the salt-sensitive genotypes. Genotype KUG 529 showed maximum increase in catalase activity with application of $0.5 \mathrm{mM} \mathrm{SA}$. $\mathrm{NaCl}$ induced inhibition of CAT activity was also recorded in wheat (Erdal et al., 2011). According to Simaei et al. (2011) application of SA increases the activity of antioxidant enzymes and could ameliorate the toxic effects generated from $\mathrm{NaCl}$ in soybean.

Ascorbate peroxidase activity(APX): All the genotypes showed a reduction in the activity level of APX, when subjected to salt stress as depicted in Figure 8 . $45 \mathrm{mM} \mathrm{NaCl}$ caused more decline in APX activity as compared to $30 \mathrm{mM} \mathrm{NaCl}$ stress. Application of SA $(0.5 \mathrm{mM}$ and $1.0 \mathrm{mM})$ increased the activity level of APX in all the genotypes including check variety UL 338. Lower concentration of SA when applied to $30 \mathrm{mM} \mathrm{NaCl}$ stressed plants caused a significant increase in APX activity of all the genotypes. Sevengor et al. (2011) reported that on exposure to $100 \mathrm{mM}$ $\mathrm{NaCl}$, exogenous SA application significantly increased the activity of APX in pumpkin genotypes

Yield and yield contributing parameters: Salt stress significantly decreased yield and various yield contributing parameters in all the genotypes. It is envisaged from table 1,2,3\&4 that foliar application of SA helped in overcoming the deleterious effects of salinity by improving the yield attributes in plants grown under salt stress. $45 \mathrm{mM}$ salinity level caused about $14 \%$ de- crease in number of seeds in tolerant varieties and about $20 \%$ in sensitive ones. Similarly, the number of pods per plant decreased by about $32 \%$ in tolerant genotypes and about $45 \%$ in comparison to their respective controls. 100-seed weight and seed yield per plant also showed a similar trend.

Salinity induced reduction in yield has also been reported by Ghai et al. (2010) in mashbean. Improvement in yield following SA application under salt stress has been worked out in mungbean by Pooja and Sharma (2010).

\section{Conclusion}

Thus, salt stress limits plant growth by adversely affecting various physiological and biochemical processes. As SA was effective in inducing stress tolerance when applied as a foliar spray it appears that SA has regulatory role in activating biochemical pathways associated with salt tolerance mechanisms. The ameliorative effect of SA might be linked to the observable increase in RLWC and water potential of leaves. SA treatments also enhanced the level of antioxidant system (CAT and APX in mashbean plants under $\mathrm{NaCl}$ stress and reduced the hydrogen peroxide and malondialdehyde content. The elevated antioxidant system counters the oxidative stress as well as other direct effects of $\mathrm{NaCl}$ stress in plants that helped in overcoming the deleterious effects of salinity and improved the yield contributing parameters. Also lower concentration of SA proved to be more effective to ameliorate the adverse effects of salt stress.

\section{ACKNOWLEDGEMENTS}

I acknowledge deep sense of gratitude to Punjab Agricultural University, Ludhiana, Punjab, India for providing me with required facilities to conduct the research.

\section{REFERENCES}

Ahmad, S., Wahid, A., Rasul, E. and Wahid, A. (2005). Comparative morphological and physiological responses of green gram genotypes to salinity applied at different growth stages. Botanical Bulletin of Academia Sinica, 46: 135-42

Andre, N., Jose, T.P., Joaquim, E.F. and Carlo- Eduardo, B. D. A. (2006). Effect of salt stress on antioxidative enzymes and lipid peroxidation in leaves and roots of 
salt-tolerant and salt-sensitive maize genotypes. Environmental and Experimental Botany, 56: 87-94

Anonymous (2009). Anti-waterlogging project, department of irrigation and drainage, Punjab Government.

Anonymous. (2012). Project coordinaters report. All India Coordinated Research Project on MULLa RP. Pp:17

Bajji, M., Kinet, J. M and Lutts, S. (2001). The use of the electrolyte leakage method for assessing cell membrane stability as a water stress tolerance test in durum wheat. Plant growth regulation, 1: 1-10

Barz, H.D., and Weatherley, P.E., (1962). A re-examination of the relative turgidity technique for estimating water deficits in leaves. Australian Journal of Biological Sciences, 15:413-428

Breusegem ,F., V., Vranova, E., Datt, J. F. and Inze, D. (2001) The role of active oxygen species in plant signal transduction. Plant Science, 161: 405-414

Chance ,M. and Maehly, A. C. (1995). Assay of catalases and peroxidases. Methods in Enzymology, 2: 764-817

Cheng,W.,J., Yan, L.,S. and Dong, H.,C. (2012). Changes in photosynthetic rate, water potential, and proline content in kenaf seedlings under salt stress. Canadian Journal of Plant Science, 92(2): 311-319.

Cho ,U. and Park, J. (2000). Mercury induced oxidative stress in tomato seedlings. Plant science, 156(1):1-9

Delavari, P. M., Baghizadeh, A., Enteshari, S. H., Kalantari, K. M., Yazdanpanah, A. and Mousavi, E. A. (2010). The effects of salicylic acid on some of biochemical and morphological characteristic of Ocimum Basilicucm under salinity stress. Australian Journal of Basic and Applied Sciences, 4 (10): 4832-4845

Dhindsa, R. S. and Motowe, W. (1981) Drought tolerance in two mosses: correlation with enzymatic defense against lipid peroxidation. Journal of Experimental Botany, 32: 79-91

El-Bassiouny, Hala M.S., and Bekheta, M. A. (2005). Effect of salt stress on relative water content, lipid peroxidation, polyamines, amino acids and ethylene of two wheat cultivars. International journal of agriculture \& biology, 7 (3): 363-368

Erdal, S., Aydın, M., Genisel, M., Taspınar, M.S., Dumlupinar, R., Kaya, O. and Gorcek, Z. (2011). Effects of salicylic acid on wheat salt sensitivity. African Journal of Biotechnology, 10 (30): 5713-5718

Fahramand, M., Mahmoody, M., Keykha, A., Noori, M. and Rigi, K. (2014) Influence of abiotic stress on proline, photosynthetic enzymes and growth. International Research Journal Applied and Basic Science, 8(3): 257265

Ghai, N., Kaur, H., Kaur, J., Sandhu, J. S. and Singh, I. (2010). Influence of salinity on growth and yield attributes in mashbean (Vigna mungo L.) genotypes. Journal Research of Punjab agricultural University, 47: 58-66

Ghai, N., Kaur, R., Pahwa, K., Kaur, J. and Singh, I. (2014). Ameliorative effects of salicylic acid on some physiological and biochemical attributes in mashbean (Vigna mungo L. hepper) under $\mathrm{NaCl}$ stress. International journal of advanced research, 2(3): 942-955

Gunes, A., Inal, A., Alpaslan, M., Eraslan, F., Bagei, E. G. and Cicek, N. (2007). Salicylic acid induced changes on some physiological parameters symptomatic for oxidative stress and mineral nutrition in maize ( $\mathrm{Zea}$ mays L.) grown under salinity. Journal of Plant Physiology, 164: 728-736

Heath, R. L. and Packer, L. (1969). Photoperoxidation in isolated chloroplast. I. Kinetics and stoichiometry of fatty acid peroxidation. Archives of Biochemistry and Biophysics, 125: 189-198

Hussein, M. M., Balbaa, L. K. and Gaballah, M. S. (2007) Salicylic acid and salinity effects on growth of maize plants. Research Journal of Agriculture and Biological sciences, 3: 321-328

Joseph, B. and Jini, D. (2011). Development of salt stress tolerant plants by gene manipulation of antioxidant enzymes. Asian Journal of Agricultural Research, 5(1): $17-27$

Karlidag, H., Yildirim, E. and Turan, N. (2009). Salicylic acid ameliorate the adverse effect of salt stress on strawberry. Science Agriculture (Piracicaba,Braz), 66 (2): $180-187$

Kaur, H. (2009) Physiological changes associated with salinity stress in mashbean (Vigna mungo L. Hepper). M.sc. Thesis, Punjab agricultural University, Ludhiana, India.

Kaur, R. (2011) Ameliorative effects of salicylic acid on physiological changes associated with salinity stress in mashbean (Vigna mungo L. Hepper). M.Sc. Thesis, Punjab Agricultural University, Ludhiana, India.

Khan, N. A., Syeed, S., Masood, A., Nazar, R. and Iqbal, N. (2010). Application of salicylic acid increases contents of nutrients and antioxidative metabolism in mungbean and alleviates adverse effects of salinity stress. Internationl journal of plant biology, 1: 1-8

Mohammadreza, S. , Amin, B. , Forogh, A., Hossin, M. and Sorayya, S. (2012). Response of Brassica napus L grains to the interactive effect of salinity and salicylic acid. Journal of Stress Physiology and Biochemistry, 8 (2): $159-166$

Molassiotis, A. N., Sotiropoulos, T., Tanou, G., Kofidis, G., Diamantidis, G. and Therios, I. (2006). Antioxidant and anatomical responses in shoot culture of the apple rootstock. MM 106 treated with $\mathrm{NaCl}, \mathrm{KCl}$, mannitiol or sorbitol. Biologia Plantarum, 50(1): 61-68

Nakano, Y. and Asado, K. (1987). Purification of ascorbate peroxidase from spinach chloroplasts: its activation in ascorbate - depleted medium and reactivation by monodehydro-ascorbate radical. Plant Cell Physiology, 28: $131-40$

Parida, A. K. and Das, A. B. (2005) Salt tolerance and salinity effects on plants: a review. Ecotoxicology and Environmental Safety, 60: 324-349

Pooja and Sharma, K. D. (2010) Salicylic acid induced amelioration in growth, biochemical metabolites and yield of mungbean (Vigna radiata L.) under salinity stress. Indian Journal of Plant Physiology, 15 (3): 219225

Purcarea, C. and Cachita-Cosma, D. (2010) Studies regarding the effects of salicylic acid on maize (Zea mays L.) seedling under salt stress. 20(1): 63-68 Seria Stiintele Vietii Vasile Goldis University, Romania.

Sevengor, S., Fikret, Y., Kusvuran, S. and Ellialtioglu, S. (2011). The effect of salt stress on growth, chlorophyll content, lipid peroxidation and antioxidative enzymes of pumpkin seedling. African Journal of Agricultural Research, 6 (21): 4920-4924 
Manpreet Kaur et al. / J. Appl. \& Nat. Sci. 8 (4): 1786-1792 (2016)

Shakya, S. K. and Singh, J. P. (2010). New drainage technologies for salt-affected waterlogged areas of southwest Punjab, India. Current Science, 99(2): 204-212

Silva, C., Martinez, V. and Carvajal, M. (2008). Osmotic versus toxic effects of $\mathrm{NaCl}$ on pepper plants. Biologia Plantarum, 52(1): 72-79.

Simaei,1. M., Nejad, R. A. K., Saadatmand, S., Bernard, F. and Fahimi, H. (2011). Effects of salicylic acid and nitric oxide on antioxidant capacity and proline accumulation in Glycine max L. treated with $\mathrm{NaCl}$ salinity. African Journal of Agricultural Research, 6 (16): $3775-3782$

Vellikova, V., Yordanov, I. and Edreva, A. (2000) Oxidative stress and some antioxidant systems in acid rain treated bean plants. Plant Science, 151: 59-66 